СТАРОДУБЦЕВА Наталья Анатольевна - аспирант Брянского государственного университета им. академика И.Г. Петровского (241023, Россия, г. Брянск, ул. Бежицкая, 14)

СЫЧЕВА Екатерина Юрьевна - кандидат социологических наук, доцент кафедры социологии и социальной работы Брянского государственного университета им. академика И.Г. Петровского (241023, Россия, г. Брянск, ул. Бежицкая, 14)

ШИЛИНА Светлана Александровна - доктор социологических наук, профессор кафедры социологии и социальной работы Брянского государственного университета им. академика И.Г. Петровского (241023, Россия, г. Брянск, ул. Бежиикая, 14; supershili2012@уапdex.ru)

\title{
УПРАВЛЕНЧЕСКИЙ ПОТЕНЦИАЛ ДИСКУРСА ЭЛЕКТОРАЛЬНЫХ ПРЕДПОЧТЕНИЙ В СВЕТЕ ЦИФРОВИЗАЦИИ КОММУНИКАТИВНОГО ВЗАИМОДЕЙСТВИЯ
}

\begin{abstract}
Аннотация. Статья посвящена актуальным вопросам перехода политических процессов в формат дистанционных технологий. В свете опасности распространения коронавирусной инфекции все чаще коммуникативное взаимодействие переходит в онлайн-пространство. Авторы статьи провели социологическое исследование, посвященное отношению электората к цифровизации политических процессов в условиях пандемии новой коронавирусной инфекции COVID-19. Методом послужил онлайн-опрос, который базируется на информационных технологиях. Анализ результатов показал, что большинство не принимает применение дистанционных технологий в политических (в частности, в электоральных) процессах. На характер электоральных предпочтений оказывает влияние ряд существенных факторов: существующий политический режим государства и его специфические черты, состояние молодежной политики, степень применения различного рода манипулятивных технологий и др. Отсюда проистекает наше внимание к вопросам управленческого потенциала дискурса электоральных предпочтений.
\end{abstract}

Ключевые слова: коммуникация, дискурс, управление, информация, власть, электорат, COVID-19, политика, цифровизация, цифровая трансформация, общество

A ктуальность обращения к управленческому потенциалу дискурса (понимаемого нами как обмен мнениями по проблемам в той или иной сфере социума [Гостенина, Качалков, Шилина 2015; Епремян, Шилина 2021]) электоральных предпочтений [Моисеенко, Шилина 2019; Лупенкова 2013] в свете цифровизации коммуникативного взаимодействия не вызывает сомнений. Этому посвящены многие современные исследования [Васильев, Коркия, Мамедов 2019; Gostenina et al. 2019; Епремян, Траханов 2020]. Переход на дистант происходит буквально во всех сферах нашей жизни; отсюда проистекает задача адаптации различных слоев населения к новым реалиям цифрового социума [Мамедов 2011]. Не обошло стороной это явление и такую область, как политические процессы, в частности электоральное поведение [Моисеенко 2019]. Особую остроту в наше время приобрели вопросы управления электоральными предпочтениями избирателей [Гостенина, Шилина 2008; Киричек 2016; Моисеенко 2020].

Поэтому правомерным, с нашей точки зрения, является обращение к проблемам перехода на онлайн-голосование при различных выборах в органы власти, что особенно актуально в преддверии выборов губернаторов, депутатов Госдумы, парламентариев в сентябре 2021 г.

В условиях существования пандемии новой коронавирусной инфекции COVID-19 в обществе во всех сферах жизнедеятельности наблюдается рост цифровых трансформаций. В образовании активную роль начало играть дис- 
танционное обучение: так, имея доступ к сети Интернет, обучающиеся могут являться полноценными участниками образовательного процесса и получать необходимые знания, не выходя из дома [Мамедов 2016; 2018]. Сегодня мы видим, что в культуре [Киричек 2009] активно внедряется проведение концертов онлайн, выставки и экскурсии в музеях можно посетить с помощью смартфона и доступа к Интернету.

Невозможно представить современные СМИ [Епремян 2019] и рекламу [Шилина 2017] только на материальных носителях: эти средства массовой коммуникации давно освоили Интернет.

В сфере здравоохранения люди, нуждающиеся в медицинской помощи, могут получить услуги, не выходя из дома, с помощью онлайн-консультации; больной, имеющий симптомы ОРВИ, может не посещать лично поликлинику, являясь распространителем опасного вируса, - достаточно позвонить по номеру телефона для вызова компетентного специалиста на дом, кроме того, активно внедряется заказ лекарственных препаратов онлайн.

Главная цель внедрения цифровизации в нашу жизнь сегодня в условиях пандемии - это, безусловно, уменьшение социальных контактов. Сокращение социальных контактов, в свою очередь, должно привести к сокращению роста распространения опасного вируса.

Политическая сфера не является здесь исключением. Политические процессы приобретают новые формы. Сегодня мы видим, что собрания органов власти различного уровня все чаще проходят в режиме онлайн.

Многие представители политических партий, органов власти имеют личные аккаунты в социальных сетях, где к ним могут обращаться различные слои населения. Это крайне важно в условиях пандемии, когда важно соблюдать социальную дистанцию и избегать нахождения в общественных местах. Так электорат может чувствовать полноправным участником политических процессов.

В формате онлайн также проводятся общественные слушания посредством использования видеоконференции с возможностью голосования. Например, 17 декабря 2020 г. состоялась ежегодная пресс-конференция президента РФ Владимира Путина в режиме видеоконференции. Как сообщают в прессслужбе Кремля, глава государства вышел на видеосвязь из своей резиденции в Ново-Огарево, а представители федеральных и зарубежных СМИ работали в зале Центра международной торговли 1 .

Мы стоим на пороге внедрения онлайн-голосования на выборах и референдумах, о чем свидетельствует проведенные в мае 2021 г. праймериз партии «Единая Россия» (внутрипартийные выборы, во время которых члены и сторонники партии определили, кто из их соратников получил право выдвижения в Государственную думу и законодательные собрания субъектов РФ под эгидой партии) в формате онлайн с привлечение портала Госуслуги.

Ниже представлены результаты социологического исследования на тему «Отношение электората к цифровизации политических процессов в условиях пандемии новой коронавирусной инфекции COVID-19».

Было важно установить: доволен ли электорат политикой, проводимой органами власти в целях предупреждения распространения новой коронавирусной инфекции COVID-19; изменились ли политические предпочтения населения за время пандемии; как оценивает электорат эффективность мер правительства РФ по борьбе с коронавирусной инфекцией и поддержке экономики; владеет ли население актуальной информацией о мерах правительства РФ по борьбе с

1 Официальный сайт Президента РФ. Доступ: http://kremlin.ru/ (проверено 06.06.2021). 
коронавирусной инфекцией и поддержке экономики; каким является отношение народа к ускорению цифровой трансформация политических процессов; каково отношение электората к онлайн-голосованию на выборах, к подписанию петиций онлайн; какова степень владения информацией о формах трансформации политических процессов в деятельности органов власти, местного самоуправления, организаций.

Обратимся к диаграмме, где представлено гендерное распределение респондентов. Так, в социологическом исследовании приняли участие 65 женщин и 60 мужчин, что в процентном соотношении составляет 52\% и $48 \%$ соответственно (см. рис. 1).

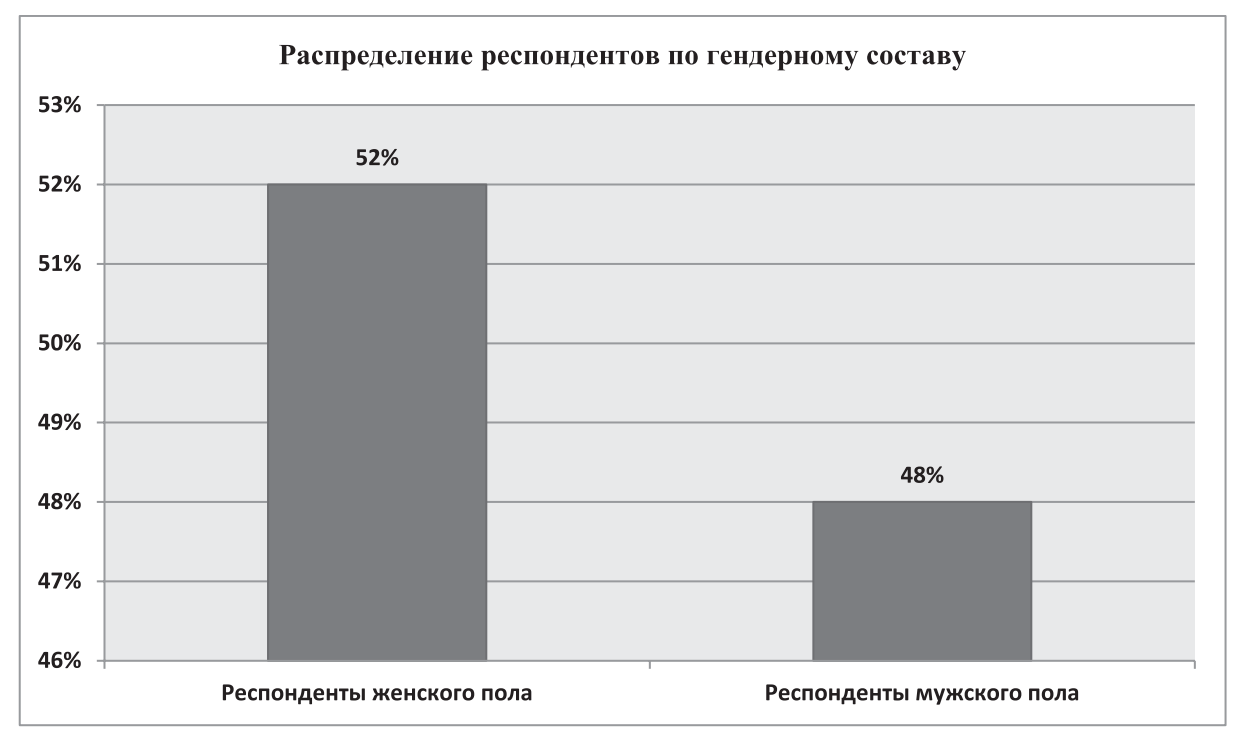

Рисунок 1. Распределение респондентов по гендерному признаку

Данные, отображенные в диаграмме на рис. 2, представляют собой результаты ответов на вопрос: «Довольны ли Вы политикой, проводимой органами власти в целях предупреждения распространения новой коронавирусной инфекции COVID-19?»

Так, каждый второй, принявший участие в опросе, недоволен данной политикой, каждый четвертый доволен, и каждый четвертый не смог определиться с ответом. Результаты ответов на вопрос могут являться индикатором оппозиционных настроений в обществе.

О том, подверглись ли изменениям политические предпочтения электората с момента возникновения пандемии, говорит диаграмма на рис. 3.

Обратившись к данным диаграммы, можно сделать вывод, что политические предпочтения большей части опрошенных претерпели изменения («да» ответили $45 \%$ опрошенных), $30 \%$ затруднились ответить на данный вопрос (см. рис. 3).

Об оценке эффективности мер правительства РФ по борьбе с коронавирусной инфекцией и поддержке экономики сообщает нам диаграмма на рис. 4. Максимально высокую оценку мерам поставил каждый второй участник опроса, на балл ниже меры оценил каждый пятый, оценку в три балла выставили $12 \%$ опрошенных, $18 \%$ респондентов дали оценку в два балла, минималь- 


\section{Довольны ли Вы политикой, проводимой органами госвласти в целях предупреждения распространения коронавирусной инфекции?}
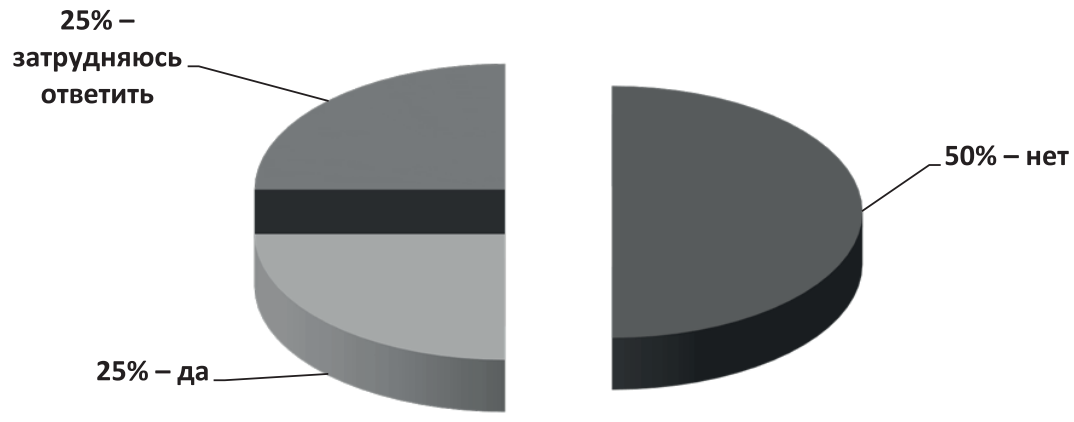

Рисунок 2. Отношение электората к политике, проводимой органами власти в целях предупреждения распространения COVID-19

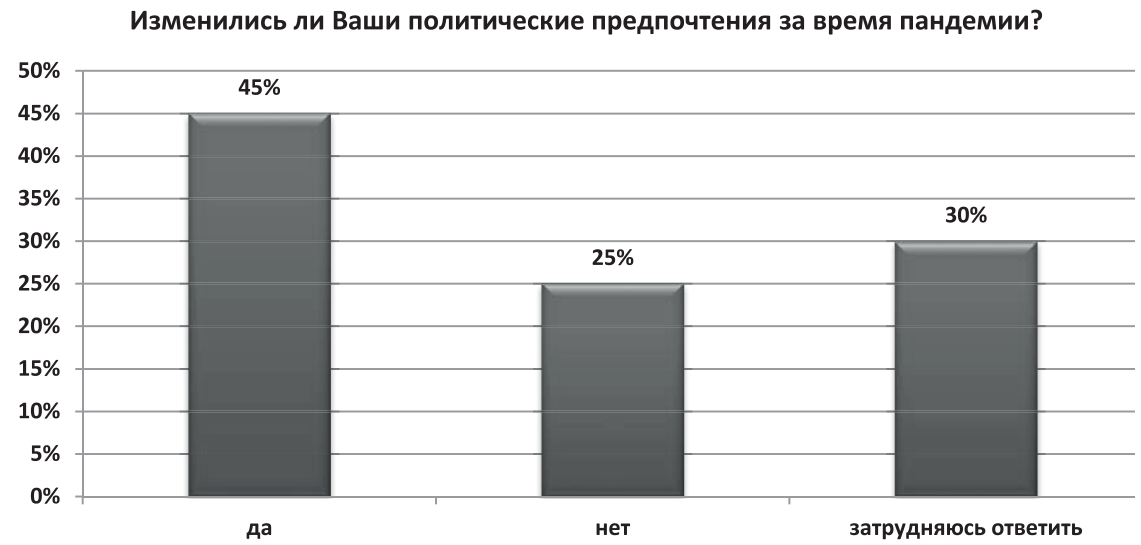

Рисунок 3. Политические предпочтения электората

ный балл никто из опрошенных не поставил. Можно сделать вывод, что население высоко оценивает меры правительства РФ по борьбе с коронавирусной инфекцией и поддержке экономики (см. рис. 4).

О том, способствует ли пандемия ускорению цифровой трансформации политических процессов, говорит диаграмма на рис. 5. Так, большинство опрошенных (73\%) ответили, что пандемия способствует цифровизации политики (см. рис. 5).

Обратимся к диаграмме на рис. 6, где представлены результаты ответов на вопрос: «Как вы считаете, будет ли целесообразной замена стандартной процедуры голосования на выборах онлайн-голосованием?»

Подавляющее большинство опрошенных считают, что она не будет являться целесообразной (см. рис. 6).

В условиях пандемии растет число онлайн-петиций. Следующий вопрос анкеты: «Известно ли вам, что существуют интернет-платформы с возможностью подписания петиций онлайн?» Каждый второй респондент знает о воз- 
Дайте оценку эффективности мер правительства РФ по борьбе с коронавирусной инфекцией и поддержке экономики

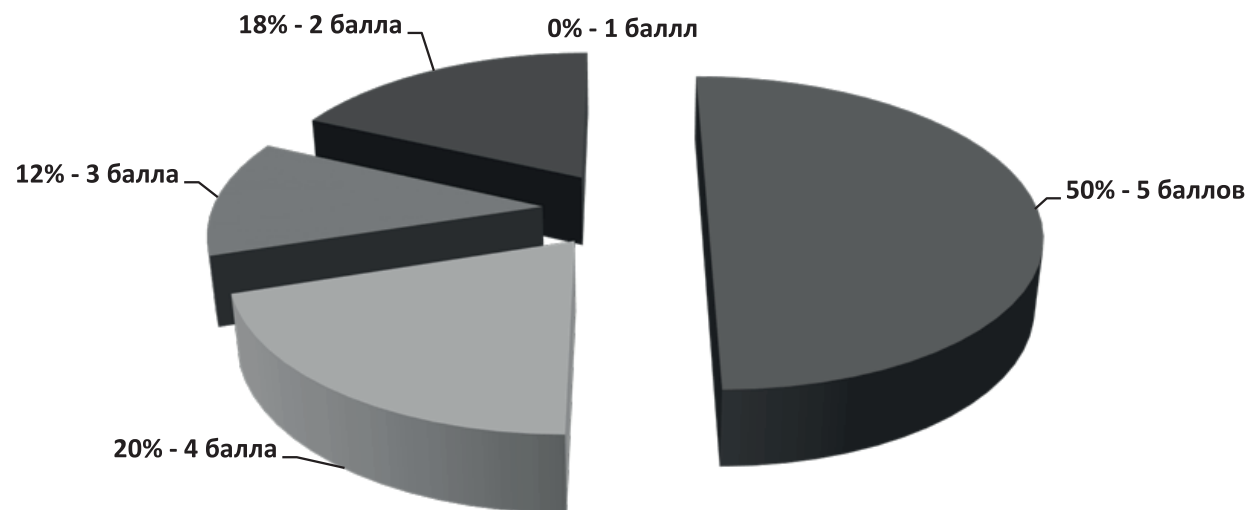

Рисунок 4. Оценка эффективности мер правительства РФ по борьбе с коронавирусной инфекцией и поддержке экономики

\section{Способствует ли пандемия ускорению цифровой трансформации} политических процессов?

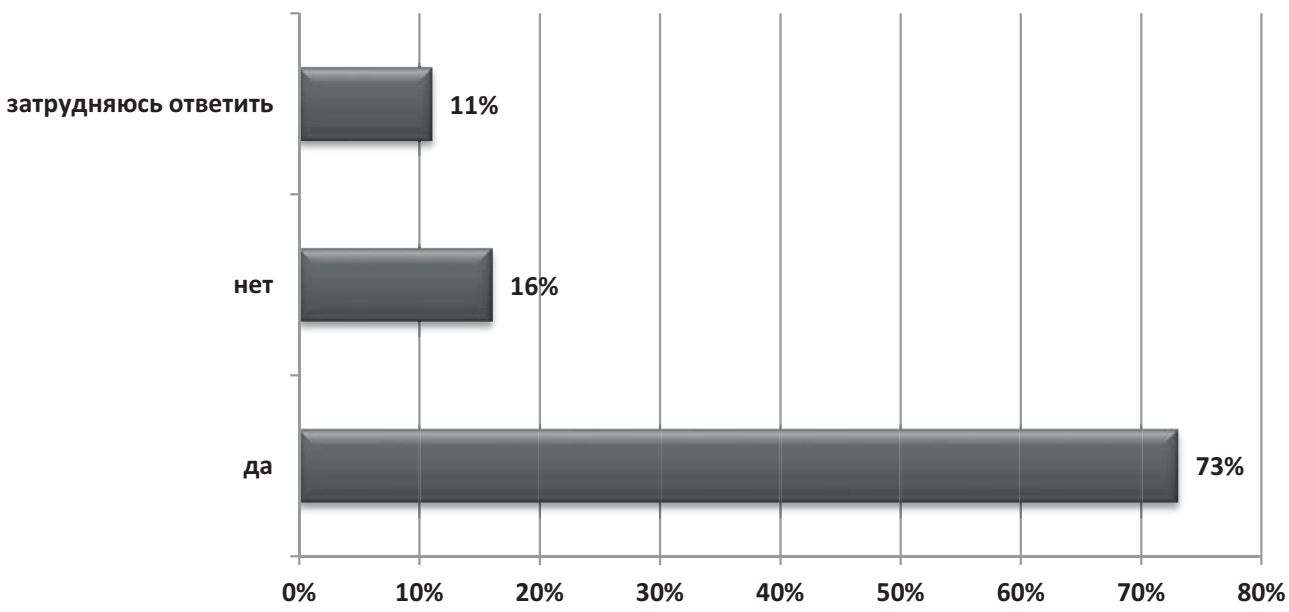

Рисунок 5. Цифровая трансформация политических процессов

можности подписания петиций в режиме онлайн, $30 \%$ респондентов не знают о таких возможностях, остальные опрошенные затруднились ответить на данный вопрос (см. рис. 7).

В результате проведения социологического исследования были получены следующие результаты. Каждый второй, принявший участие в опросе, недоволен данной политикой, проводимой органами власти в целях предупреждения распространения новой коронавирусной инфекции COVID-19, каждый четвер- 
Как Вы считаете, будет ли целесообразной замена стандартной процедуры голосования на выборах на онлайн?

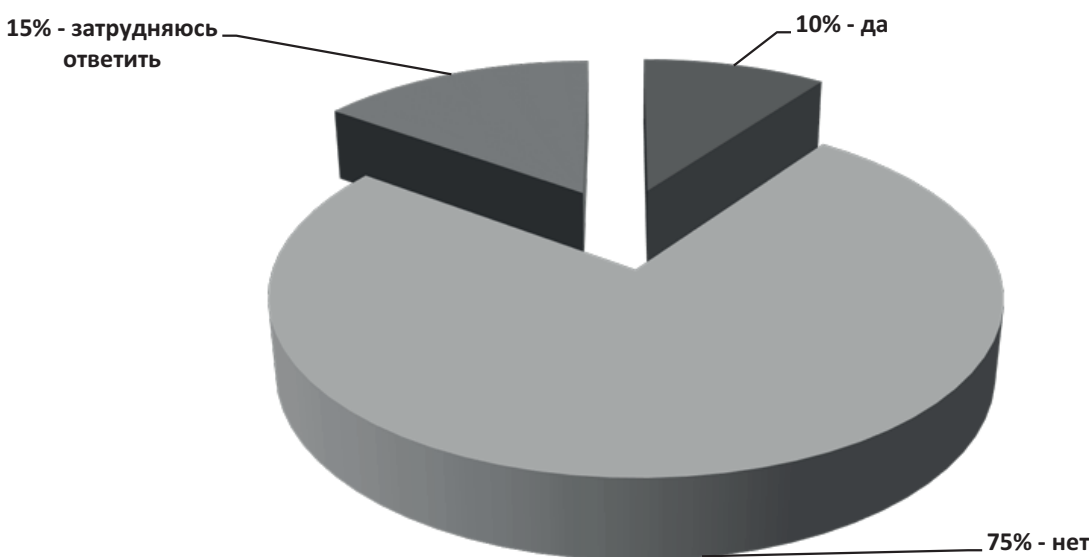

Рисунок 6. Оценка целесообразности замены стандартной процедуры голосования на выборах онлайн-голосованием

\section{Известно ли Вам, что существуют интрнет-платформы для подписания} петиций онлайн?

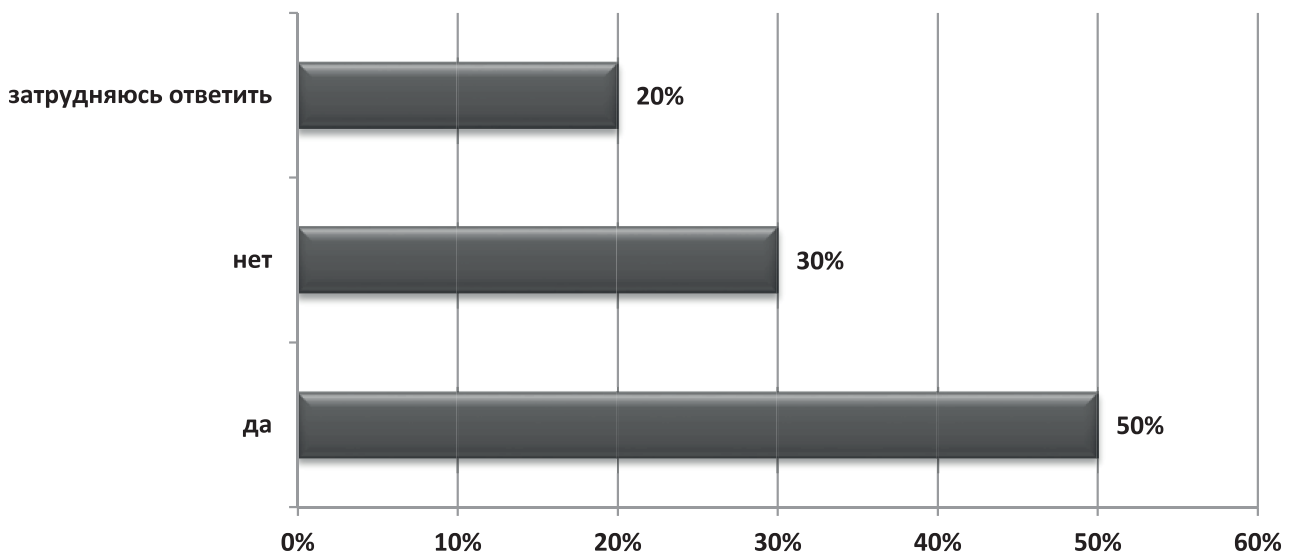

Рисунок 7. Информированность граждан о существовании интернет-платформ с возможностью подписания петиций онлайн

тый доволен. Было выявлено, что политические предпочтения большей части опрошенных претерпели изменения.

Электорат дал высокую оценку эффективности мер правительства РФ по борьбе с коронавирусной инфекцией и поддержке экономики. Большинство опрошенных отметили, что пандемия способствует цифровизации политики. Участники опроса отметили, что замена стандартной процедуры голосования на выборах онлайн-голосованием не будет являться целесообразной. 
Каждый второй респондент знает о возможности подписания петиций в режиме онлайн. Также большинство опрошенных видят недостатки в цифровизации политических процессов. В ходе исследования респондентами были выделены следующие формы трансформации политических процессов: онлайн-голосование, подписание петиций онлайн, проведение собраний политических партий, органов власти, организаций в формате видеоконференции.

Результаты ответов на вопросы анкеты могут являться индикатором оппозиционных настроений в обществе.

Статья издается на средства договора № 12/21 от 10.03.2021 на выполнение научно-исследовательских работ.

\section{Список литературы}

Васильев А.В., Коркия Э.Д., Мамедов А.К. 2019. Культура коммуникаций в условиях информационной глобализации. М.: ООО «МАКС Пресс». 160 с.

Гостенина В.И., Шилина С.А. 2008. Управление вербальным социолингвистическим кодом субъекта власти в коммуникативном процессе. М.: Изд-во МГИМО(У). $208 \mathrm{c}$

Гостенина В.И., Качалков А.Ю., Шилина С.А. 2015. Управленческий дискурс как технология социального взаимодействия субъекта власти и социума. - Власть. № 8. С. 128-133.

Епремян Т.В. 2019. Отношение читателя печатных СМИ к дискурсу рекламного медиатекста: социологическое исследование. - Текст в языковом, историческом, философском пространстве: сборник научных трудов (отв. ред. В.В. Никульцева). М.: Изд-во МФЮА. С. 234-247.

Епремян Т.В., Траханов А.В. 2020. Рекламный дискурс в аспекте виртуализации социального пространства в период пандемии 2020 года. - Влияние качества жизни на формирование ценностной структуры населения России: сборник материалов всероссийской научной конференции с международным участием. М.: Изд-во МГУ. С. 96-97.

Епремян Т.В., Шилина С.А. 2021. Дискурс социального пространства города в условиях цифровизации. - Дискурс социальных проблем в социокультурном, образовательном, языковом пространстве в период пандемии коронавируса: сборник материалов всероссийской научно-практической конференции с международным участием. Брянск. С. 25-31.

Киричек П.Н. 2009. Культуры никогда не бываетв избытке...-Государственная служба. № 1(57). С. 61-65.

Киричек П.Н. 2016. Информационная культура в арсенале управленца. - Инновационные технологии в управлении: сборник научных статей. М.: ООО «МАКС Пресс» С. 4-10.

Лупенкова Е.Ю. 2013. Ценностные ориентации российского электората: управленческий анализ: на примере Брянской области: дис. ... к.соц.н. М.: РУДН. 178 с.

Мамедов А.К. 2011. Реальность будущего или кризис социальных теорий? Социология образования. № 2. С. 17-25.

Мамедов А.К. 2016. Проблема оснований социального знания (полемические заметки). - Экономика. Социология. Право. № 3(3). С. 68-80.

Мамедов А.К. 2018. Научное знание: классическое наследие и мода. Экономика. Социология. Право. № 1(9). С. 91-100.

Моисеенко Н.А. 2019. Роль СМИ в реализации управленческих социальнополитических процессов. - Журналістыка-2019: стан, праблемы і перспектывы: 
сборник трудов конференции. Минск: Изд-во Белорусского государственного университета С. 68-71.

Моисеенко Н.А. 2020. Электоральное поведение молодежи: управленческий аспект. - Экономика. Социология. Право. № 2(18). С. 80-88.

Моисеенко Н.А., Шилина С.А. 2019. Дискурс электоральных предпочтений: управленческий аспект. - Дискурс. № 12(38). С. 185-199.

Шилина С.А. 2017. Рекламный текст как объект социологических исследований дискурса. - Текст в культурном, историческом, языковом пространстве: сборник материалов международной заочной научно-практической конференции. М.: Изд-во МФЮА. С. 502-509.

Gostenina V.I., Karneev R.K., Makarova G.V., Melnikov S.L. 2019. Discursive and Visual Management Technologies in Urban Sociology. - Opcion. Vol. 35. Special Edition 24. C. 122-135.

STARODUBTSEVA Natal'ya Anatol'evna, postgraduate student at Bryansk State Academician I.G. Petrovski University (14 Bezhitskaya St, Bryansk, Russia, 241023)

SYCHEVA Ekaterina Yurıevna, Cand.Sci. (Soc.), Associate Professor of the Chair of Sociology and Social Work, Bryansk State Academician I.G. Petrovski University (14 Bezhitskaya St, Bryansk, Russia, 241023)

SHILINA Svetlana Aleksandrovna, Dr.Sci. (Soc.), Professor of the Chair of Sociology and Social Work, Bryansk State Academician I.G. Petrovski University (14 Bezhitskaya St, Bryansk, Russia, 241023; supershili2012@yandex.ru)

\section{MANAGEMENT POTENTIAL OF THE ELECTORAL PREFERENCES DISCOURSE IN THE CONTEXT OF THE COMMUNICATION DIGITALIZATION}

\footnotetext{
Abstract. The article is devoted to the popular contemporary theme: the use of the digital technologies in the political processes. Because of the coronavirus pandemic communication is increasingly moved online. The authors conducted a sociological study of the mass attitude to the political digitalization in the context of the coronavirus pandemic. They used the method of the online survey, based on information technologies. The analysis of the results demonstrated that the majority does not accept the use of digital technologies in political processes, especially during the election. A number of significant factors influence the nature of electoral preferences: the contemporary state political regime and its specific features, the actual state youth policy and its specifics, the use some manipulative technologies, etc. This are the main aspects of the research interest to the management potential of the electoral preferences discourse.

Keywords: communication, discourse, management, information, power, electorate, COVID-19, politics, digitalization, digital transformation, society
} 